Global warming makes its mark everywhere

\section{- International treaty planned Serious obstacles lie ahead}

TAKEN together, 1990 and 1991 may well be best remembered as the years in which the foundations were laid for an international convention to control global warming. An intergovernmental conference at which negotiations will begin is to be held in Washington in February.

At the World Climate Conference at Geneva in November 1990, governments agreed that a convention should be signed at the United Nations Conference on Environment and Development in Brazil in June 1992. But it is not yet clear whether that document will contain binding protocols to limit emissions of carbon dioxide and other greenhouse gases, and to slow deforestation, or whether it will simply be a legal framework on which to build.

Much rests with the United States, which has so far refused to follow other industrialized governments (notably those of Europe) in setting a target to limit carbon dioxide emissions. Throughout 1990, President George Bush stuck to his "no regrets' strategy allowing for cuts of greenhouse gas emissions only when there are other benefits to be won - energy efficiency, stratospheric ozone protection, smog abatement and the like.

Yet the US position may be influenced by the appearance, perhaps later this month, of the long-awaited Evans report from the US National Academy of Sciences. This will recommend policies the US government should adopt to tackle global warming. The report is expected to blaze a trail beyond no-regrets. With congressional backing, the report could provide the non-partisan weight needed to budge the White House from its opposition to carbon dioxide emission controls.

The climate negotiators will be hoping to build on the environmental achievement of 1990 - the London meeting that tightened the Montreal Protocol's controls on stratospheric ozone-depleting chemicals.

The pledge by the industrialized nations to make available $\$ 240$ million by 1993 , with more to follow, to help developing countries comply with the protocol, is regarded both as a sign of goodwill and as a precedent for the global warming convention. But the US administration, which inevitably foots a large part of bills like these, is alarmed at the sums of money that might be needed to make a global warming treaty palatable.

The negotiators can at least draw on a solid consensus about the rate of global warming over the next century predicted by the numerical climate models. The now-completed report of the Intergovernmental Panel on Climate Change (IPPC) suggests that, with no greenhouse gas controls, the average global temperature is likely to rise by $0.3^{\circ} \mathrm{C}$ each decade. But reliable regional predictions, and hence a reasonable assessment of the impact of global warming, will require substantially greater computer power and are still a distant prospect.

The economic analysis of strategies to limit and adapt to a changing climate is also largely an uncharted wilderness such studies as there have been (mostly by

\section{Munich}

EUPHORIA, the predominant emotion of 1989 in both halves of the German science community, was replaced in 1990 by a palpable sense of fear. In the West, researchers first feared physical invasion, then being 'infected', from the East. And in the East, people foresaw the end of their institutes and their careers in a brutal wave of rationalizations.

As the year ended, Western researchers felt sheepish but relieved that their worst fears had not come true. Science spending was up, and Western institutes could easily handle the small number of immigrants from eastern Germany.

And as it has turned out, most researchers in eastern Germany have also been spared the axe, at least for a year. That is the effect of the intervention, in July, of the then West German science advisory council (Wissenschaftsrat) and of the West German Länder (states), which have jointly resolved on an evaluation of eastern science potential.

Even so, the evaluation exercise has stirred up resentment in the East. Researchers there resent the short time they will be allowed to prove their worth as well as the sometimes-patronizing attitudes of Wissenschaftsrat evaluators.

Once Wissenschaftsrat completes its evaluation in 1991, science in eastern Germany is likely to be given a new lease on life. Towards the end of last year, the granting agency DFG (Deutsche Forschungsgemeinschaft) and the Max Planck Gesellschaft (MPG) took reassuring steps.

Assuming that the newly reelected gov- advocates of one policy option or another) have produced widely different answers.

Meanwhile, the US administration is also preparing for a long hot future. The Environmental Protection Agency has been quietly expanding its Adaptation $\mathrm{Di}$ vision - an office whose sole purpose is to find ways of living in a greenhouse world. (Canada's new 'Green Plan' calls for the same.) And Department of Energy planners are accelerating their search for alternatives to fossil fuels, while the Department of Agriculture is looking into new crops for what could become a Saharan South and temperate North in the United States.

In some European countries, carbon taxes on fossil fuels are already on the agenda. The European Commission is drawing up plans for a carbon tax throughout its 12 member states. But the British government's recent declaration of opposition to carbon taxes outside the transport sector may cause these plans to be shelved.

\title{
Old fears overtaken by doubt
}

ernment of Chancellor Helmut Kohl continues to give science a high priority despite other pressures on its budget, both organizations promised ample investment in the eastern Länder.

DFG has moved boldly and quickly into the East, first (last February) by offering joint grants to eastern and western groups and then, on the day after reunification on 4 October, by allowing eastern Germans to apply directly for DFG money. By the end of the year, more than DM20 million ( $\$ 13.3$ million) had been granted for 141 cooperative projects. Eastern Germans also applied for DM 15 million in direct grants in the last three months alone.

DFG expects nearly DM100 million to be included in its 1991 budget for the eastern Länder, nearly 10 per cent of its 1990 budget.

MPG hesitated longer, but announced in November that in 1991 it would support as many as ten eastern research groups. In the process, MPG has also abandoned its policy of independence from university affiliation so as to encourage the resetlement of top groups at eastern universities, which suffered badly under the old regime.

There are no such white knights for the science-oriented industry of former East Germany. Companies such as the optical engineers Carl Zeiss Jena and the electronics manufacturer Robotron may have been lauded, in the past, for the best R\&D in the Soviet bloc, but as 1990 ended, they and other companies were about to succumb to old debts and to the desire of most western German industrialists to start afresh in the east. 